Original Research

\title{
Designing Ergonomic Product to Ease of Eating Parkinson's Patients, According to the Assessment of the Body Comfort Situation
}

\author{
Bahram Ipaki \\ MSc of Industrial Design, Faculty of Islamic Design, Tabriz Islamic Art University, Tabriz, Iran
}

\begin{tabular}{|c|c|c|}
\hline \multicolumn{2}{|c|}{ Article Info } & Abstract \\
\hline Original Article & & \multirow{4}{*}{$\begin{array}{l}\text { Background and Objectives: Parkinson's is a progressive disease of the ner- } \\
\text { vous system that by affecting the body movements, affects patients' quality of life } \\
\text { and makes daily tasks like eating, difficult and time consuming for them. The aim } \\
\text { of this study was to improve the comfort situation of Parkinson patient when eating } \\
\text { by identifying ergonomic problems, and designing product for this. }\end{array}$} \\
\hline Received: & $2018 / 05 / 16$ & \\
\hline Accepted: & $2018 / 12 / 02$ & \\
\hline Published Online & $2018 / 12 / 26$ & \\
\hline
\end{tabular}

DOI: $10.30699 /$ jergon.6.3.6

Use your device to scan and read the article online

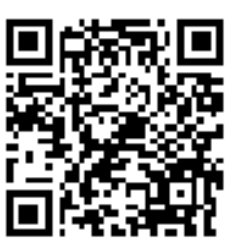

Corresponding Information

\section{Bahram Ipaki,}

MSc of Industrial Design, Faculty of Islamic Design, Tabriz Islamic Art University, Tabriz, Iran

Methods: 12 Parkinson's patients were chosen by simple random sampling method. Data was collected through a translated Interview of the Discomfort Questionnaire section of ErgoFellow Software and direct observation of patients while eating. After the final data analysis and extraction of design guidelines, design ideas were sketched and the final design was formed after AHP evaluation.

Results: Discomfort Questionnaire data (the average rate of 10.6out of 7 (1. 514)) showed that the non-ergonomic posture of hands, fingers, wrists, arms, elbows, neck, upper back (lumber), and shoulders, the discomfort rate while eating, is more intense, compared to other parts of the body . Observations have also shown that in order to near food to patient mouth, occur Non-ergonomic changes in the patient's posture. Therefore, designing product should be done using anthropometric data.

Conclusion: The results showed that reduction of mouth-to-food distance would reduce discomfort and fatigue for the Parkinson's patient. Therefore, using anthropometric data, a height-adjustable product was designed and developed that improves the position of the posture and reduces the patient's discomfort situation during eating food.

Keywords: Ergonomics, Product design, Posture, Parkinson patient eating

Email:

ipakdesign@gmail.com

Copyright (C) 2018, Journal of Ergonomics. This is an open-access article distributed under the terms of the Creative Commons Attribution-noncommercial 4.0 International License which permits copy and redistribute the material just in noncommercial usages, provided the original work is properly cited

How to Cite This Article:

Ipaki B. Designing Ergonomic Product to Ease of Eating Parkinson's Patients, According to the Assessment of the Body Comfort Situation. J Ergon. 2018; 6 (3): 55-64 
مجلة اركونومى - •IVMD-199

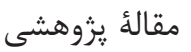

\section{طراحى محصول اركونوميك با هدف سهولت غذاخوردن در بيماران ياركينسون طبق ارزيابى وضعيت راحتى بدن

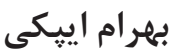

كارشناسىارشد طراحى صنعتى، گروه طراحى صنعتى، دانشكده طراحى اسلامى، دانشعاه هنر اسلامى تبريز، تبريز، ايران

\begin{tabular}{|c|c|}
\hline جكيده & اطلاعات مقاله \\
\hline 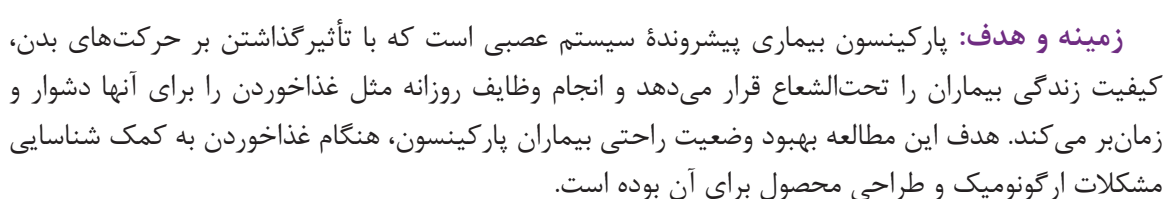 & $\begin{array}{ll}\text { تاريخ وصذيرش: } & \text { تانتخار آناين: }\end{array}$ \\
\hline 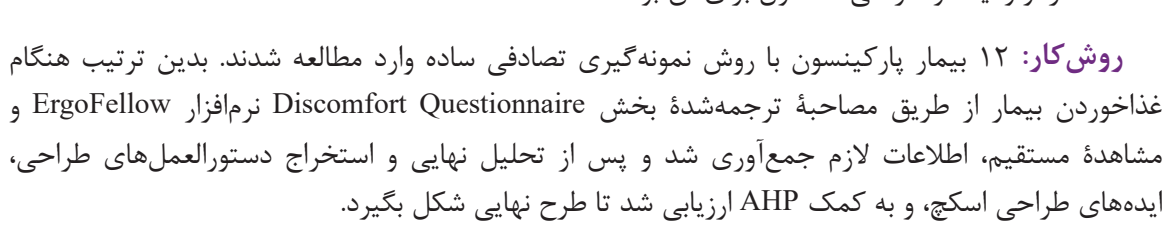 & 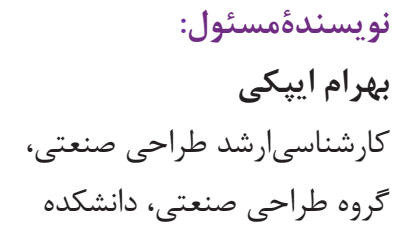 \\
\hline 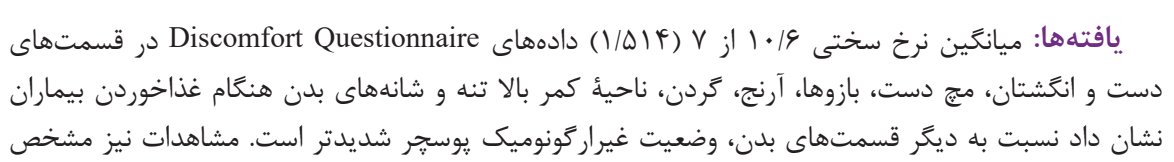 & طراحى اسلامى، دانشعاه هنر \\
\hline 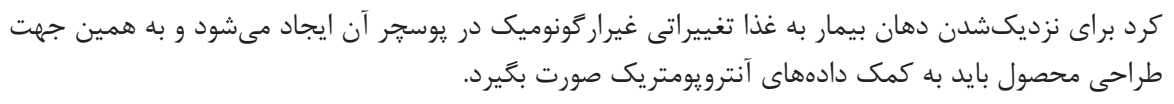 & يست الكترونيك: \\
\hline 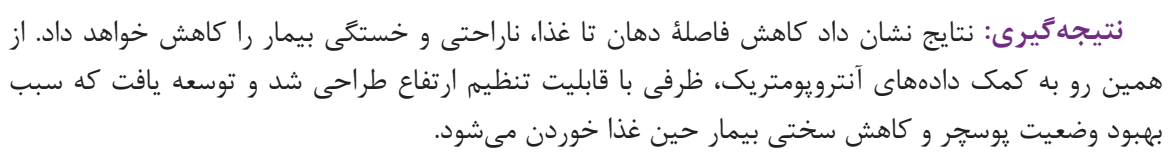 & \\
\hline وازمهاى كليدى: اركَونومى، طراحى محصول، يوسجر، غذاخوردن بيمار پاركينسون & \\
\hline
\end{tabular}

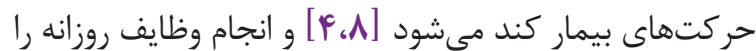

مقدمه

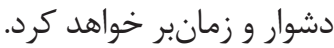

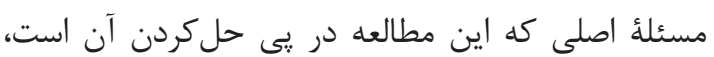

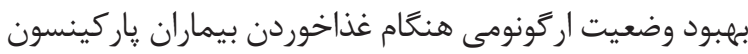

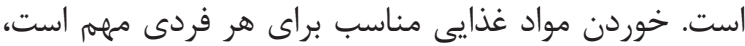

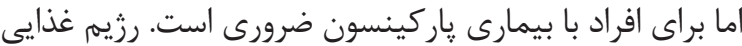

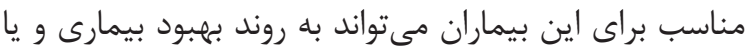

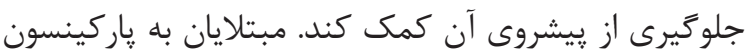

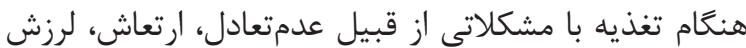

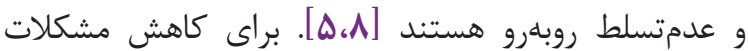

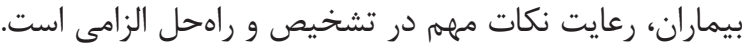

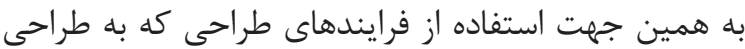

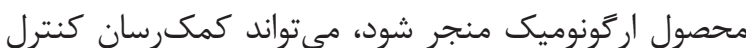

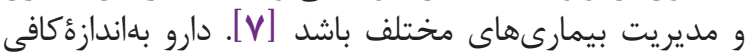

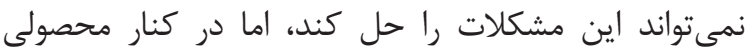

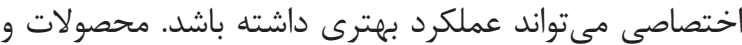

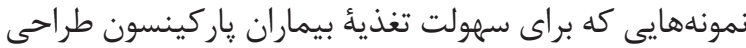

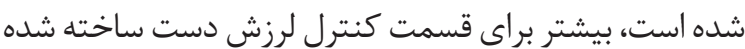

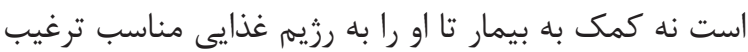

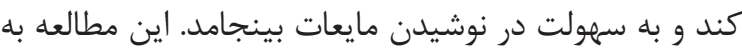

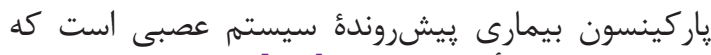

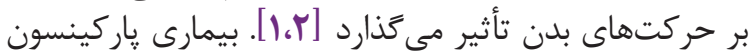

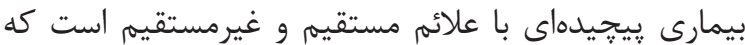

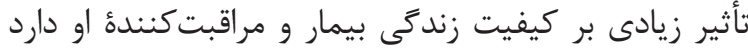

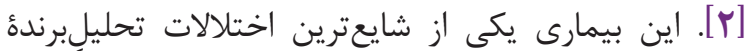

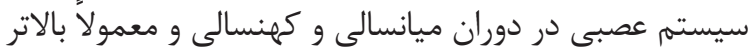

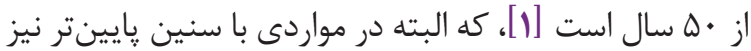

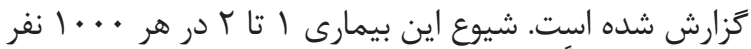

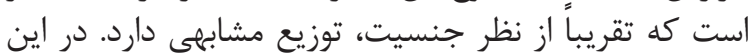

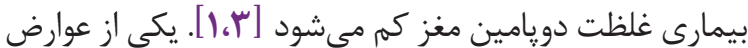

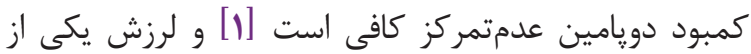

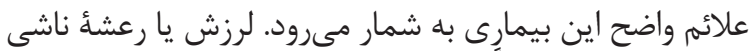

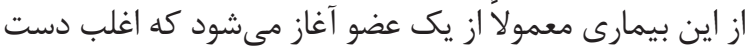

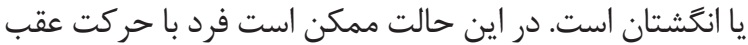

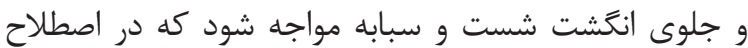

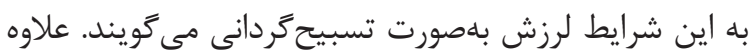

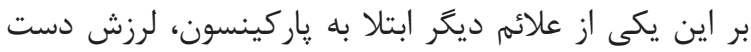

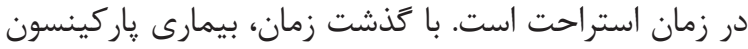

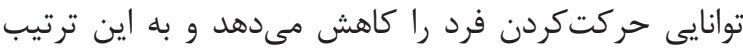


دادههاى كمى آن به كمك نرمافزار ErgoFellow صورت

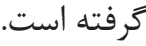

به دليل محدوديت دسترسى به بيماران ثاركينسون و

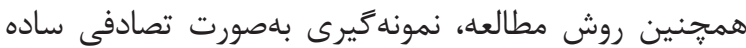

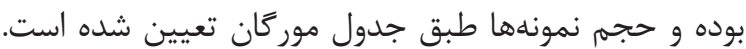

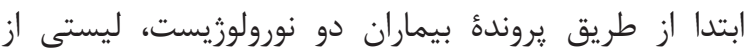

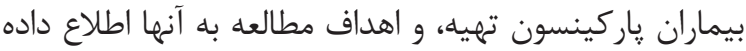

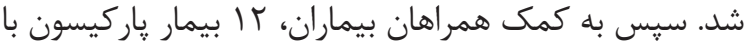

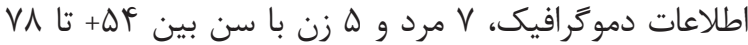

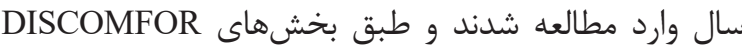
ن

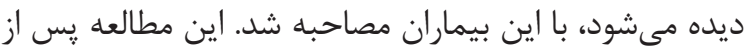

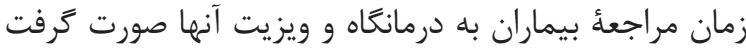

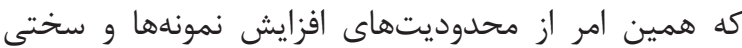

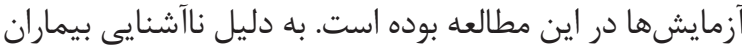

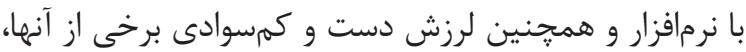

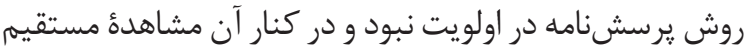

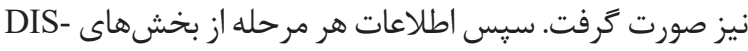
COMFOR QUESTIONNAIRE

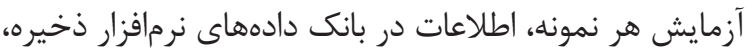

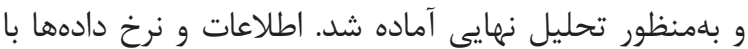

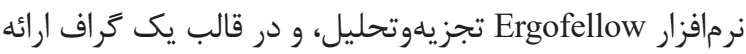

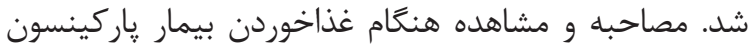

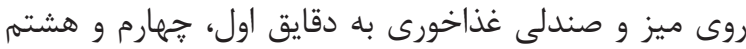

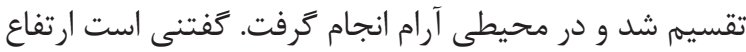

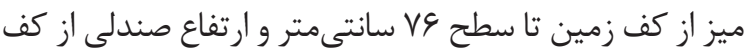

دنبال طراحى وسيلهاى اركونوميك براى سهولت تغذئو بئ بيماران

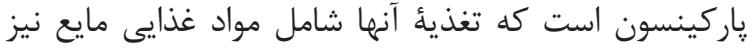

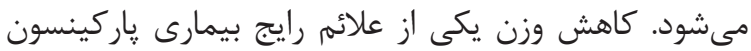

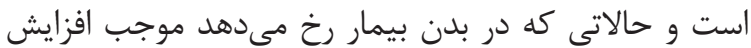

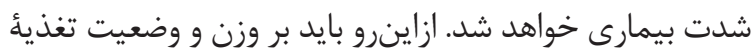

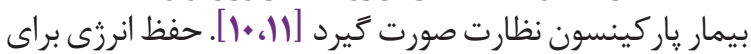

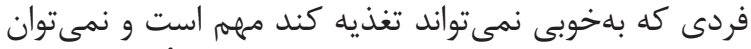

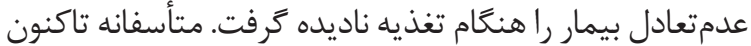

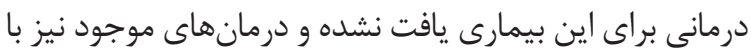

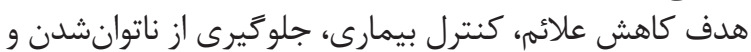

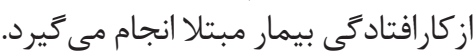

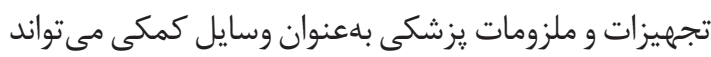

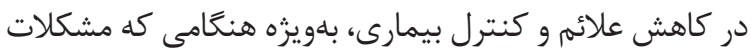

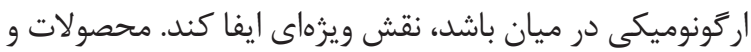

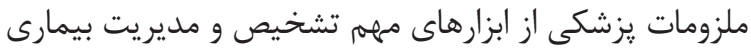

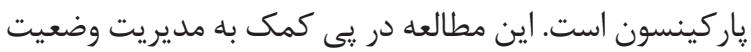

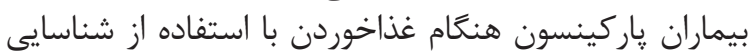

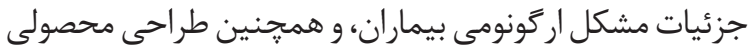

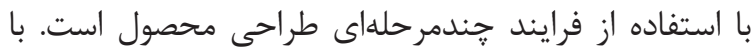

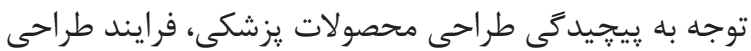

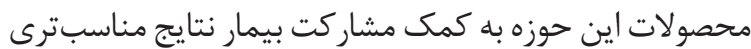

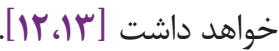

$$
\text { مواد و روشها }
$$

براى جمعآورى اطلاعات در اين مطالعه از مشاهده

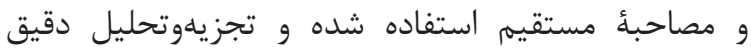

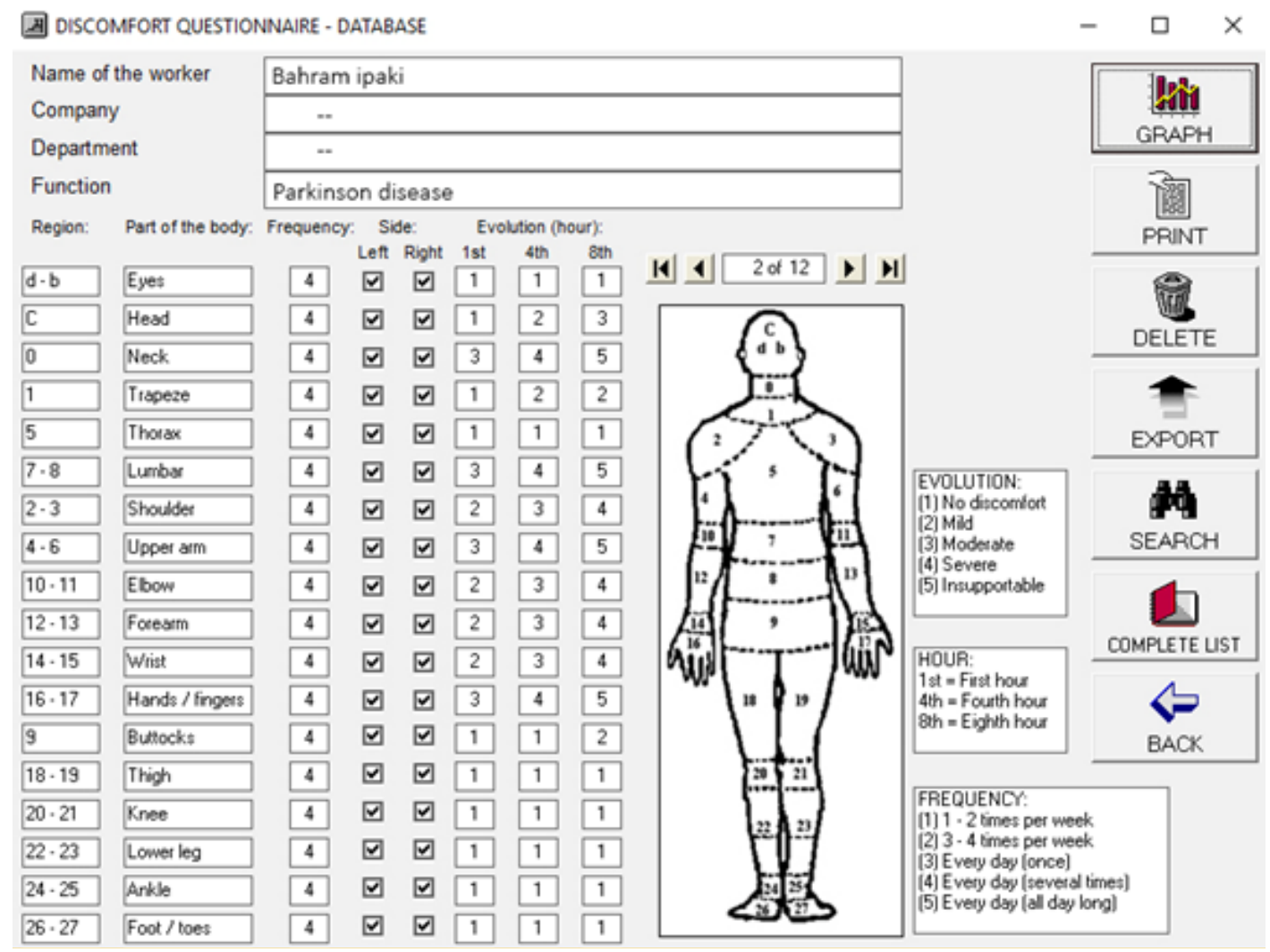

شكل ا. بخش ERIANNOITSEUQ TROFMOCSID نرمافزار wolleFogrE 


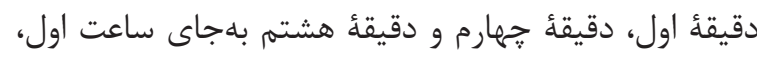

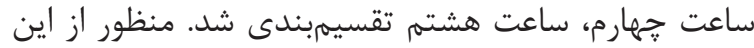

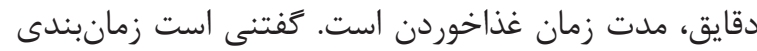

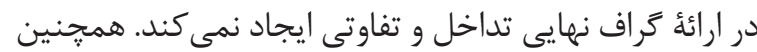

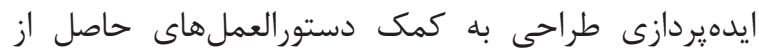

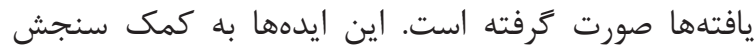

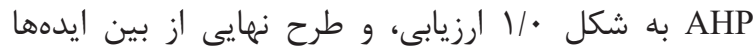

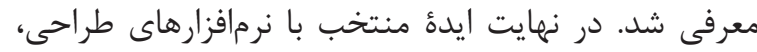

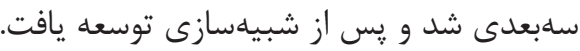

\section{يافتهها}

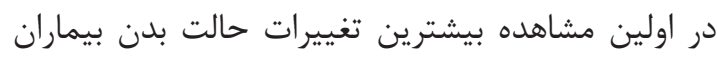

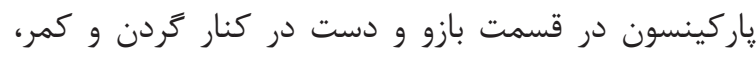

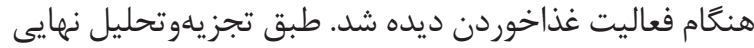

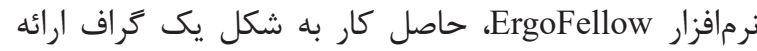
شده است كه در شكل r نشان داده مىشود.

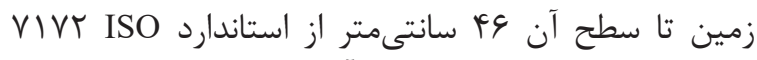

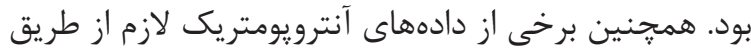

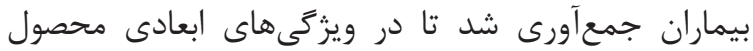

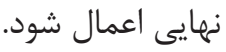

اين مطالعه به شكل كمى و كيفى بوده است و فرايند

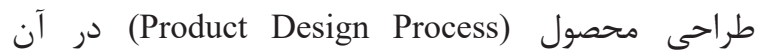
طى شده است كه شامل جمعآورى و والايش اطلاعلاعات،

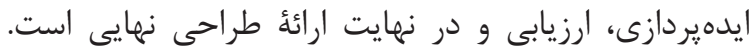

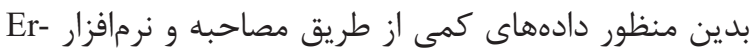

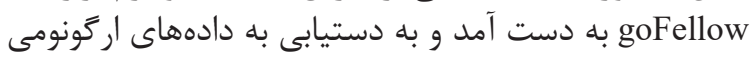

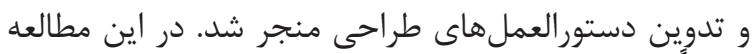

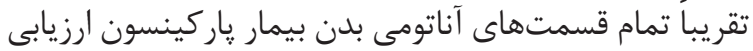

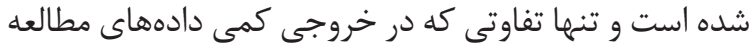

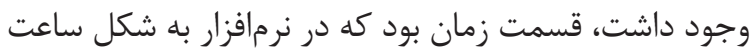

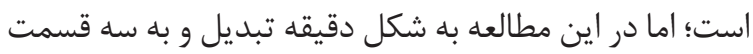

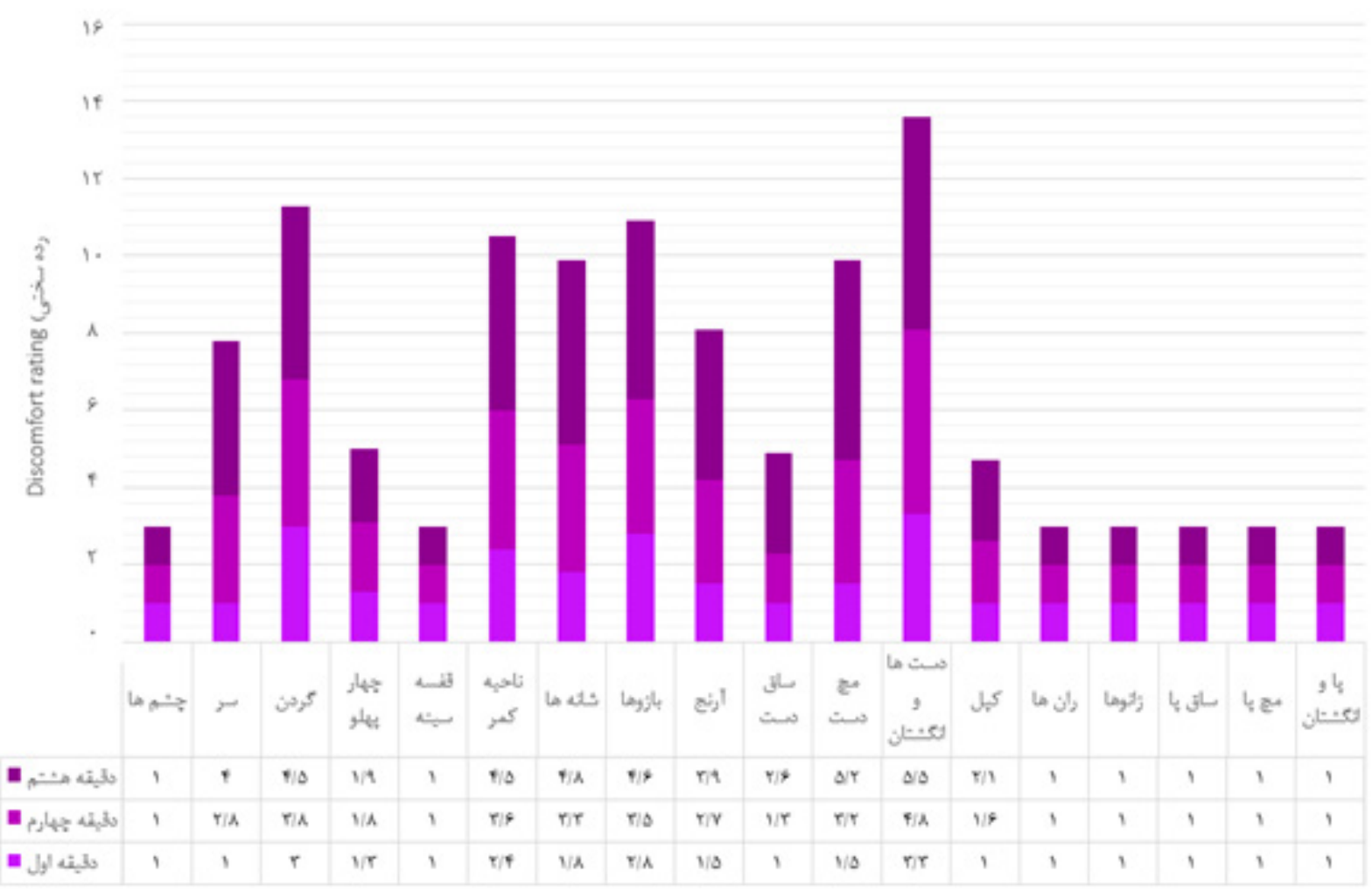

شكل r. تراف و نرخ سختى بلهدست آمده از ERIANNOITSEUQ TROFMOCSID

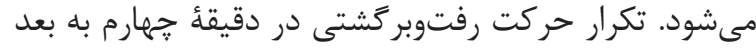

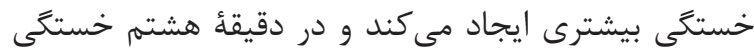

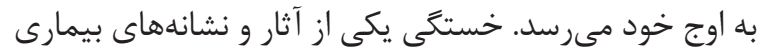

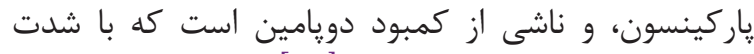

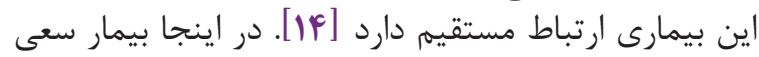

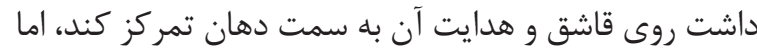

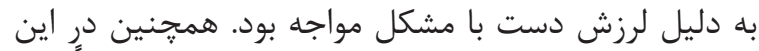
مطالعه فشار روى مج دست دئ، شانهها، سر و و آرنج نسبتاً زياد

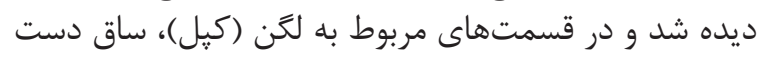

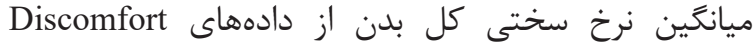
Questionnaire

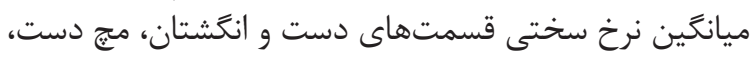

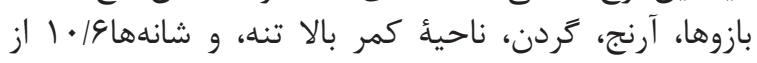

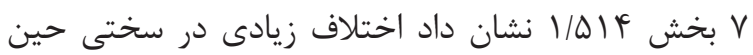

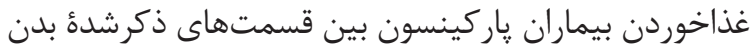

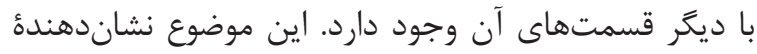

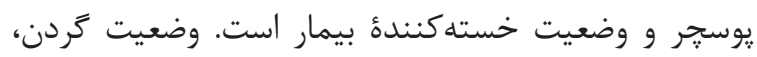

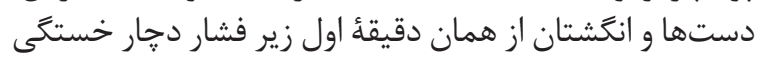


r. وضعيت يوسجر (خمشدن بيش از حد گردن و كمر)

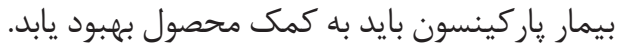

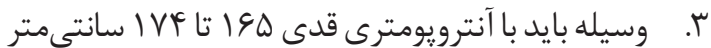
و ارتفاع استاندارد سطح مبلمان غذاخورى

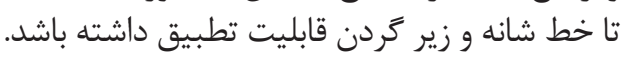
f استفاده از وسيله طراحى الىده ايجاد شود. ه. متريال ساخت محصول بايد به تأييد سازمان غذا و

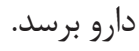

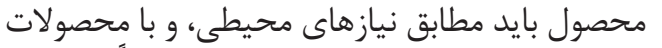

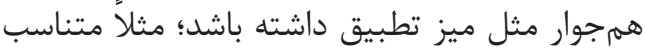
با سطح صاف طراحى شود يا ايستايى داشته باشد. V. بيمار نبايد نكران ريختهشدن غذا روى زمين باشد.
و جهار يهلو نيز فشار كمتر است. بيمار در ديگر نقاط بدن هنگًام غذاخوردن، وضعيت راحتى (comfort) داشت. از سوى ديخر مشاهده نشان داد اين بيماران در خوردن

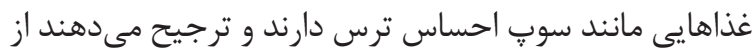

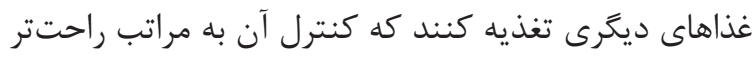

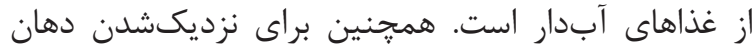

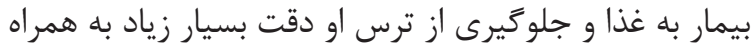

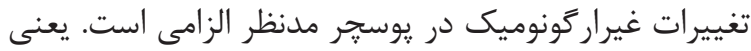

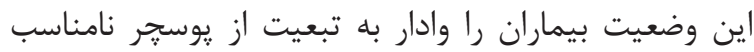

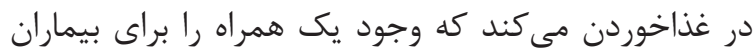

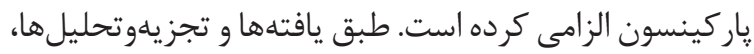
دستورالعمل هاى طراحى بلهصورت أرى ذيل استخراج شد:

I. وسيله بايد فاصلة غذا تا دهان را طبق ارتفاع سطح

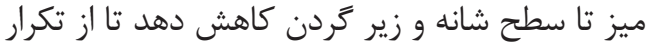

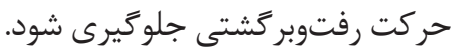

جدول 1. شاخصهاى آنترويومتريك مدنظر مطالعه براساس نمونهها

ارتفاع استاندارد مبلمان غذاخورى طبق VIVY ISO

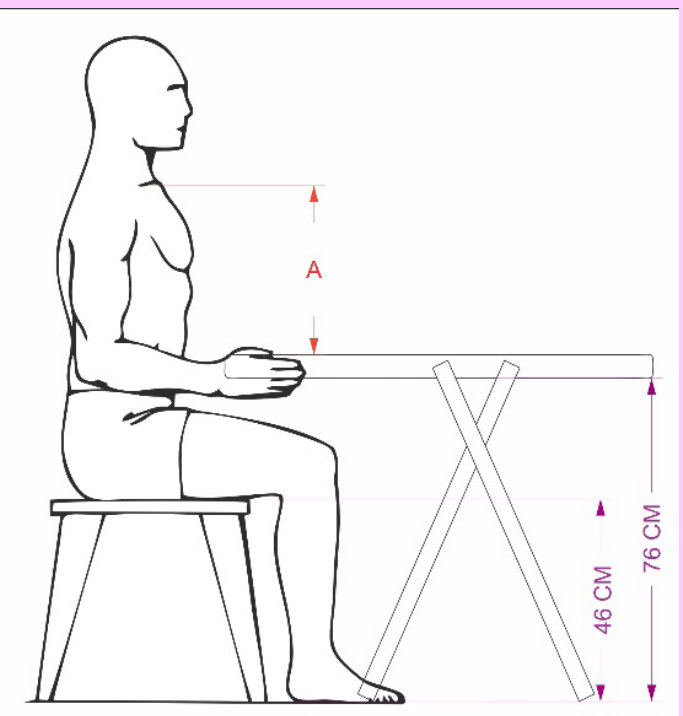

ميانكين قد و A

Aمونها

\begin{tabular}{|c|c|c|c|}
\hline & rt & 199 & n) \\
\hline خانمها: & $r T$ & 190 & nr \\
\hline ميانگين قد 199 & r & 199 & nr \\
\hline \multirow{2}{*}{ ميانگين A A A T } & r & $19 \mathrm{~V}$ & nf \\
\hline & Tr & 199 & $\mathrm{n} \Delta$ \\
\hline & TF & $19 \mathrm{~V}$ & $\mathrm{n} \&$ \\
\hline & $r \omega$ & 199 & $\mathrm{n} V$ \\
\hline آقايان: & $r \Delta$ & $|V|$ & $\mathrm{n} \wedge$ \\
\hline 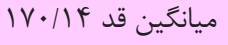 & $r V$ & IVT & nq \\
\hline \multirow{3}{*}{ rه/DV A ميانكين } & TF & 191 & n). \\
\hline & $r \wedge$ & $I V F$ & $\mathrm{n})$ \\
\hline & rq & 199 & $\mathrm{n} \| \mathrm{r}$ \\
\hline
\end{tabular}

با زحمت كمترى مواجه مىشود. اخر اين فاصله كمتر شود،

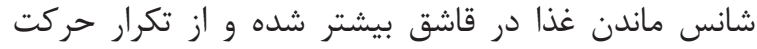

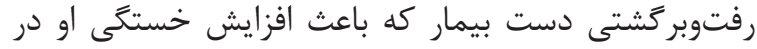

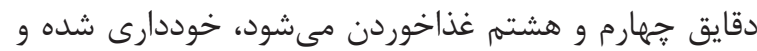
خستخى كاهش خواهد يافت. به اين ترتيب ايدههاى طراحى با تحليلهاى نعارنده

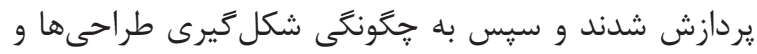

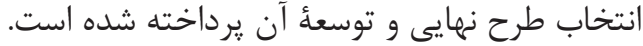

\section{جَكَونَى شكل گَيرى ايدههاى طراحى}

يس از استخراج دستورالعملهاى طراحى در يافتهها،
دادههاى آنترويومتريك مطالعه در جدول ا آمده است.

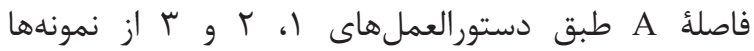

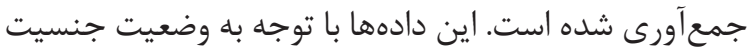

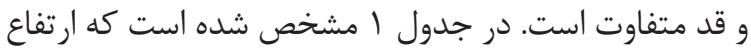

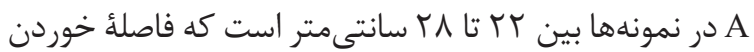

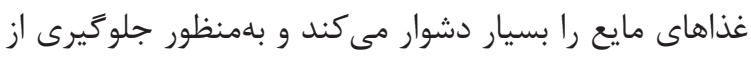

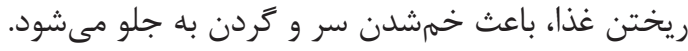

\section{بحث و نتيجه تيرى}

به نظر مىرسد كاهش ارتفاع و فاصلة غذا تا دهان بيمار

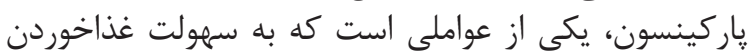

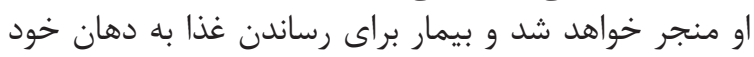




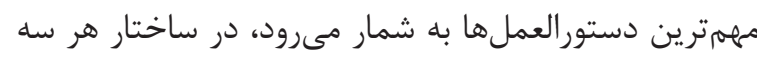

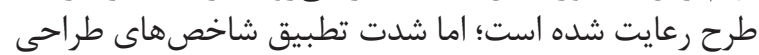

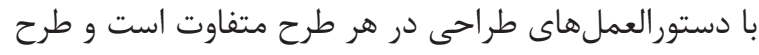
نهايى يس از ارزيابى انتخاب مى شورد
ايدهاى طراحى طبق اين دستورالعملها در سه اسكج

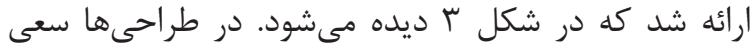

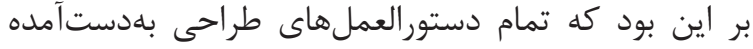

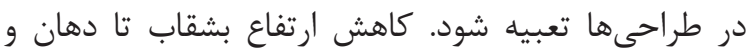

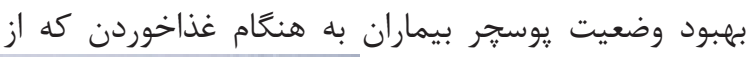
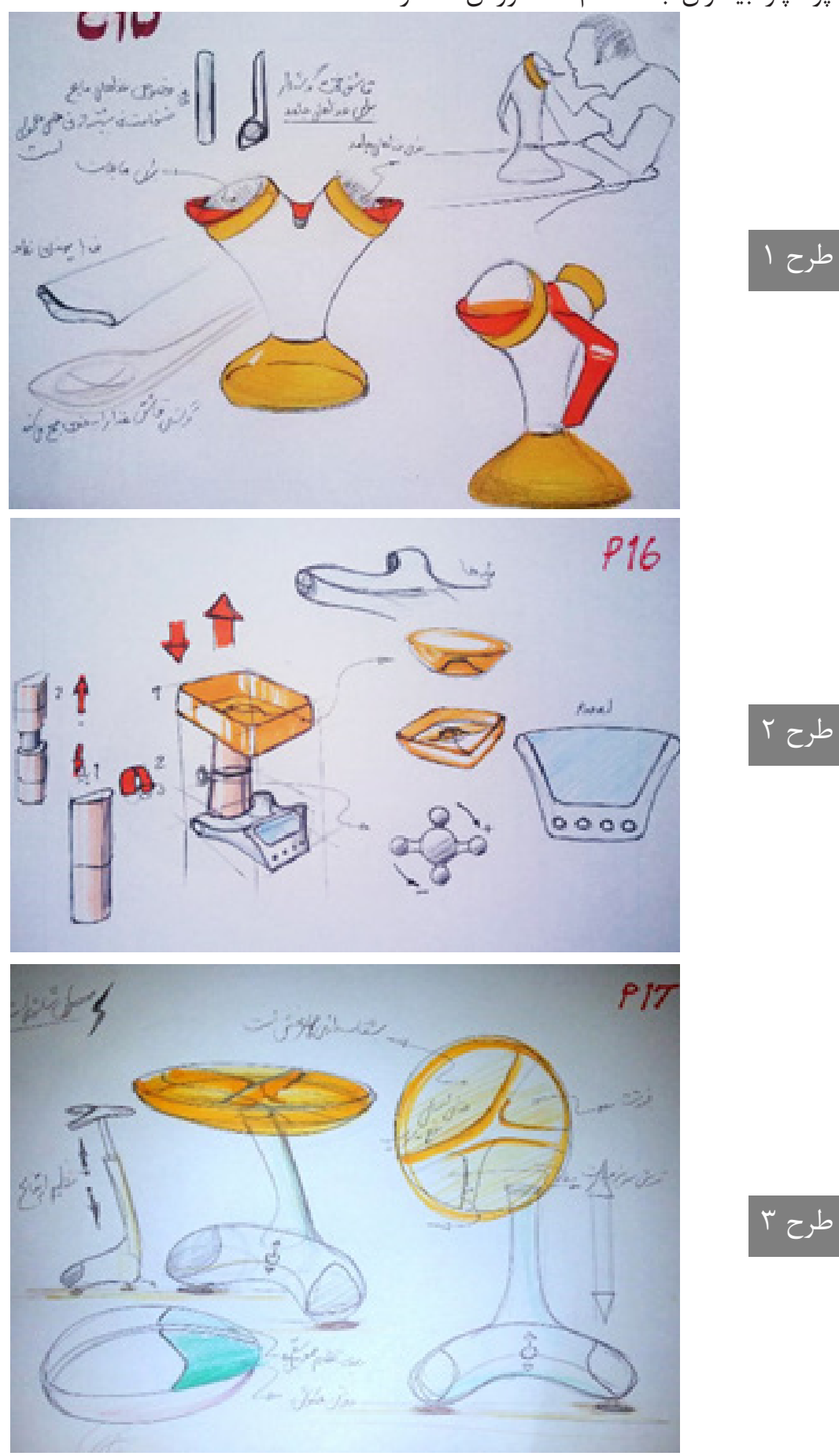

شكل r. ايده هاى اسكج شده مطالعه

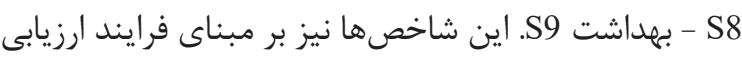

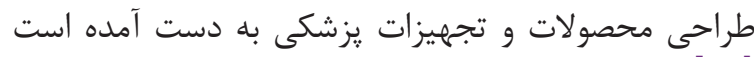

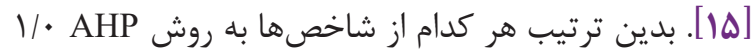

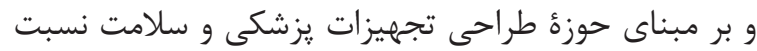

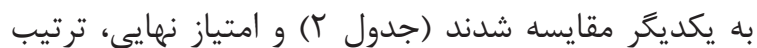

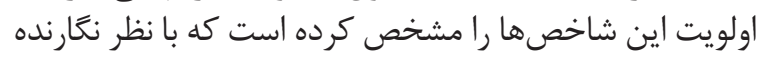

ارزيابى طراحىها

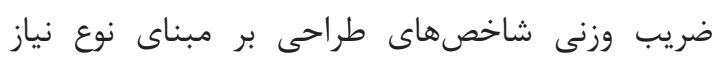

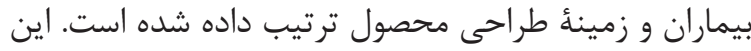

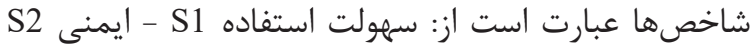

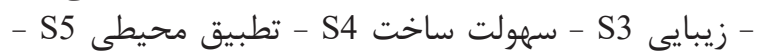

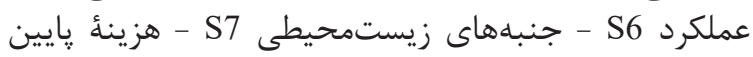


جدول r. ارزيابى شاخصهاى طراحى از طريق معيار سنجش •11

\begin{tabular}{|c|c|c|c|c|c|c|c|c|c|c|}
\hline $\mathrm{S}$ & S1 & $\mathrm{S} 2$ & S3 & S4 & S5 & S6 & S7 & S8 & S9 & $\sum$ \\
\hline $\mathrm{S} 1$ & 1 & 1 & 1 & 1 & 1 & 1 & 1 & 1 & 1 & 9 \\
\hline $\mathrm{S} 2$ & . & 1 & 1 & 1 & . & 1 & 1 & 1 & 1 & $v$ \\
\hline $\mathrm{S} 3$ & . & . & 1 & 1 & . & 1 & 1 & 1 & . & $\Delta$ \\
\hline $\mathrm{S} 4$ & . & . & . & 1 & . & . & . & 1 & . & $r$ \\
\hline S5 & 1 & . & 1 & 1 & 1 & 1 & 1 & 1 & 1 & $\wedge$ \\
\hline S6 & . & . & 1 & . & . & 1 & 1 & 1 & . & f \\
\hline $\mathrm{S} 7$ & . & . & . & 1 & . & 1 & 1 & 1 & . & r \\
\hline $\mathrm{S} 8$ & . & . & . & 1 & . & 1 & 1 & 1 & . & r \\
\hline S9 & 1 & 1 & 1 & 1 & 1 & 1 & 1 & 1 & 1 & $q$ \\
\hline
\end{tabular}

در اولويت سوم قرار كرفت كه اهميت آن نيز همجنان زياد است. شاخص زيبايى نيز يكى از مواردى است كه در جذابيت

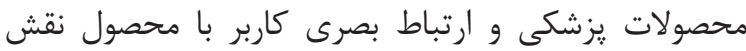

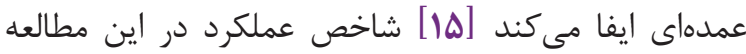

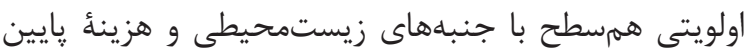

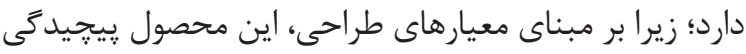

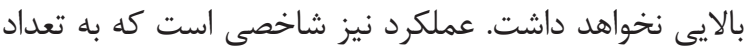

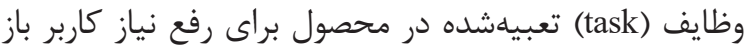

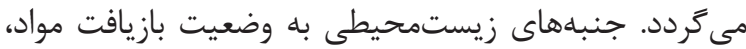

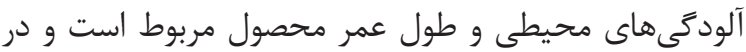

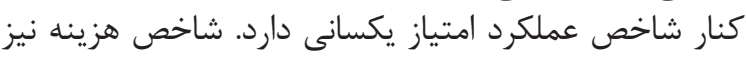

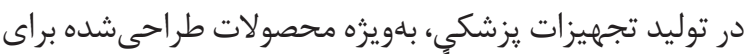

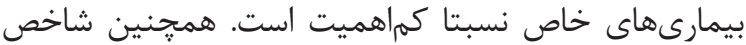

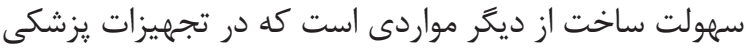

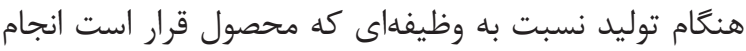

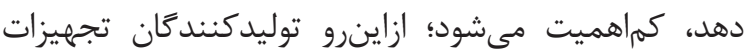

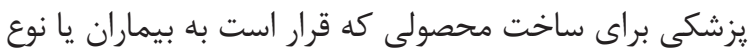

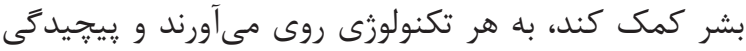

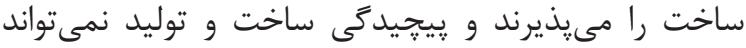

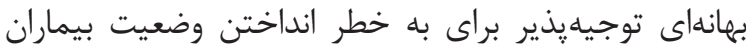

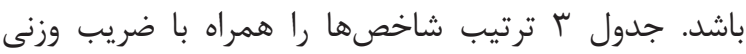

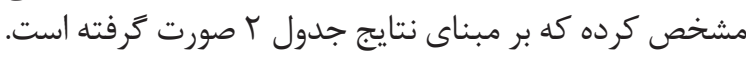

بهاعنوان متخصص طراحى صورت گرفت. بايد توجه داشت كه

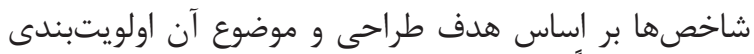

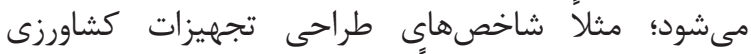

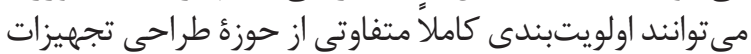
يزشكى داشته باشند.

\section{تحليل تر تيب شاخصها}

سهولت استفاده، شاخصى براى درك بيشتر بيماران

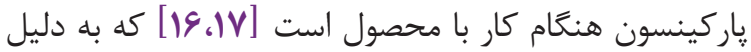

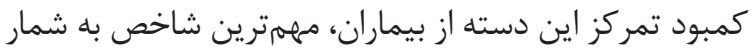

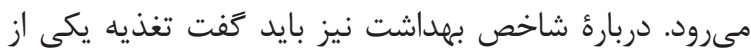

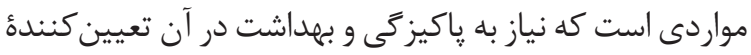

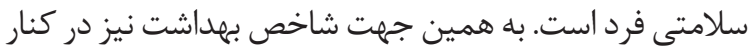
سهولت استفاده بيشترين امتياز را دارد.

شاخص تطبيق محيطى به ساختار و استاندارد تجهيزات يزشكى FDA متناسب با محصولات همرجوار اشاره مى مند

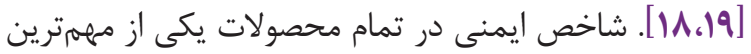

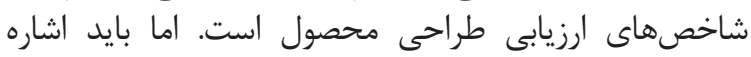

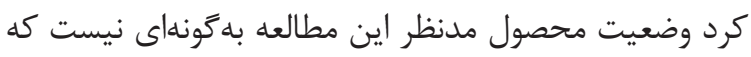

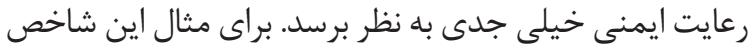

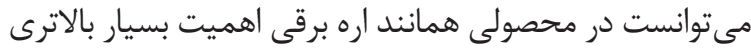

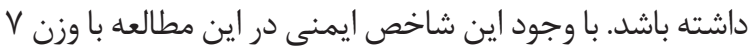

\section{ضريب}

9

9

9

$\wedge$

$\checkmark \quad$ ST

$\Delta \quad S H$

i sq

i sV

r si

r

\section{جدول r. ترتيب شاخصها بر اساس ضريب وزنى}

s)

s9

sQ

st

r

5

V

sf
سهولت استفاده

$$
\text { بهداشت }
$$

تطبيق محيطى

ايمنى

زيبايى

عملكرد

جنبههاى زيستمحيطى

هزينهُ پإيين

سهولت ساخت 


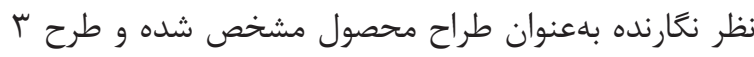
بهنوان طرح نهايى و برتر انتخاب شده است.
در نهايت به هر طرح بر اساس هريك از شاخصها وزنى ونى

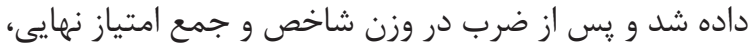

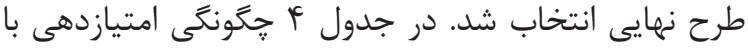

جدول f. انتخاب طرح نهايى از طريق محاسبة ضريب وزنى

\begin{tabular}{|c|c|c|c|}
\hline طرح r & طرح r & طرح 1 & شاخصهاى ارزيابى \\
\hline $9 \times 1$ & $9 \times 9$ & $9 \times \Delta$ & S1 سهولت استفاده \\
\hline $9 \times 1$ & $9 \times V$ & $9 \times 1$ & S9 بهداشت S9 \\
\hline$\Lambda \times V$ & $\Lambda \times \gamma$ & $\Lambda \times \Delta$ & S5 تطبيق محيطى S5 \\
\hline$V \times 9$ & $\gamma \times \Delta$ & $V \times \Delta$ & S2 ايمنى S2 \\
\hline$\Delta \times x^{4}$ & $\Delta \times r$ & $\Delta \times \varphi^{c}$ & S3 زيبايى S3 \\
\hline$r \times f$ & $r \times r$ & $r \times r$ & S6 عملكرد S6 \\
\hline$f_{x} y^{4}$ & $r \times r$ & $r \times r$ & S7 جنبه هاى زيستمحيطى \\
\hline$r \times r$ & $r \times r$ & $r_{x} F^{k}$ & S88 هزينهُ پايين \\
\hline$r \times \mid$ & $|x|$ & $r \times Y$ & S سهولت ساخت S4 \\
\hline$r \cdot \Lambda$ & TF. & TAT & جمع \\
\hline
\end{tabular}

و يا جامد در كنار سالاد، ماست و غيره دسترسى راحتى جإستى توسعة طرح منتخب

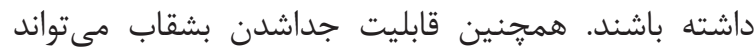

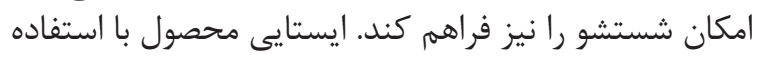

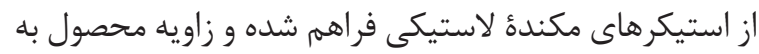

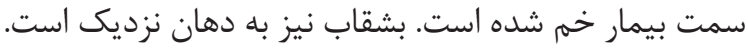

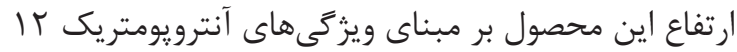

يس از ارزيابى و انتخاب طرح نهايى، طراحى محصول به نها

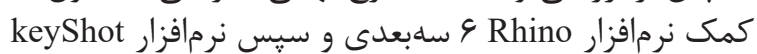

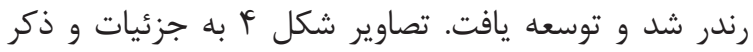

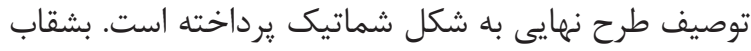
مخصوص اين اجازه را به بيماران مى دهد كه به به غذاهاى بهد آبدار
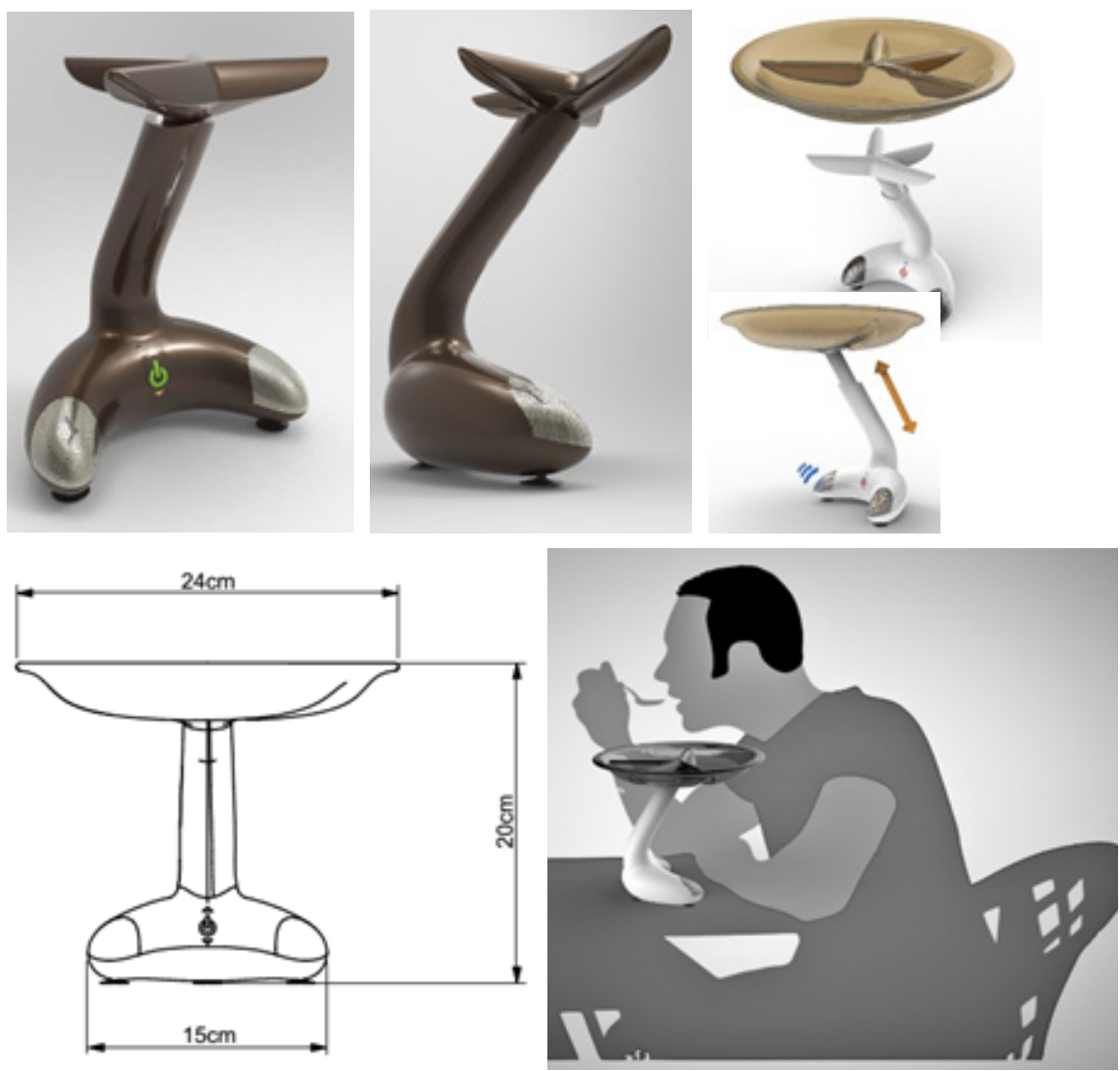

شكل F. تصوير توسعه يافتهُ محصول نهايى با توضيحات شماتيك 


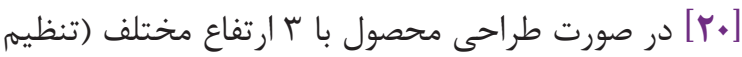

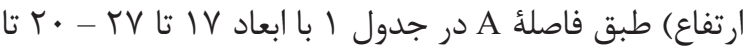

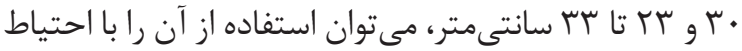

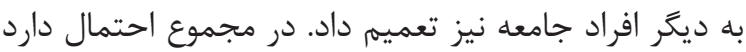

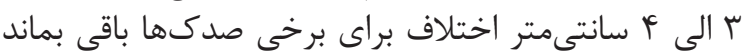

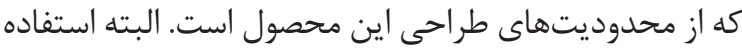

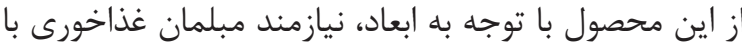

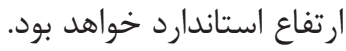

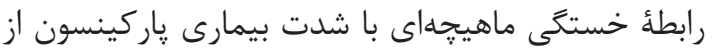

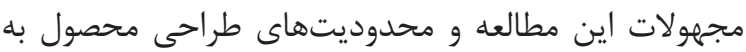

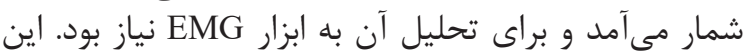

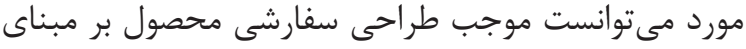

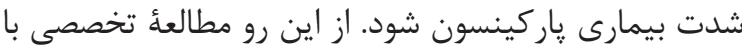

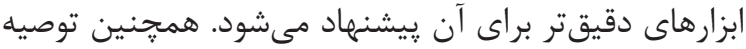

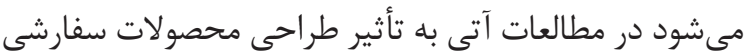

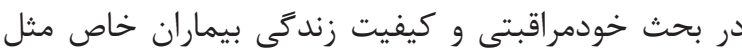

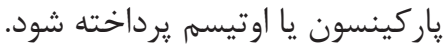

\section{ييشنهادات استفاده از اين طرح}

ا. طرح نهايى به كونهاى است كه مىتواند باعث ثبات

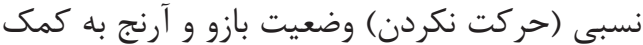

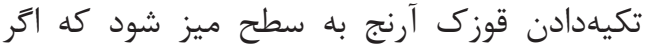

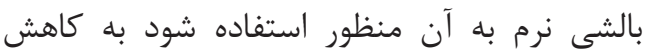
خستخى بيمار كمك مى كند.

r. به همراهان و مراقبان بيمار توصيه مىشود فاصلة غذا تا دهان بيمار را به كمك وسئ وسيلهاى إن ارتفاعدار

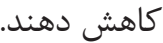

"ا. تاحد ممكن بايد سعى شود بيمار روى مبلمان غذاخورى

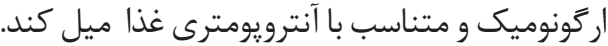

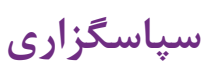

به اين وسيله از كلئُ كسانى كه در انجام مراحل اين يزوهش يارى

\section{تعارض منافع}

در اين مقاله هيجَّونه تعارض منافعى وجود ندارد.

\section{References}

1. Ali N. Understanding Parkinson's Disease: An Introduction for Patients and Caregivers. Rowman \& Littlefield Publishers; 2013.

2. Waldvogel D. Medical treatment of Parkinson's disease. Med Ther des Morb Park. 2007;64(1):15-20.

3. Hauser a. Parkinson disease. Emedicine. 2013 Jun 7;90(23):458-62.
بيمارى كه در دسترس مطالعه بودند طراحى شد (جدول

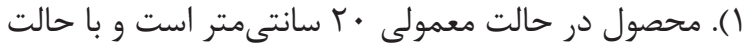

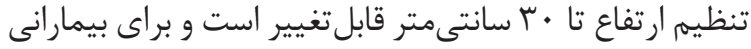

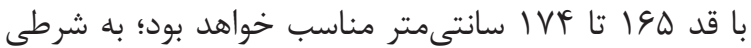

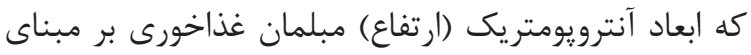

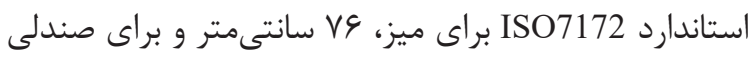

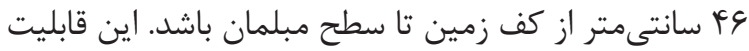

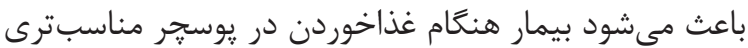
قرار گيرد.

محصول طراحىشده تا حدودى باعث كاهش سختى

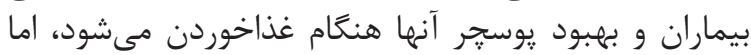

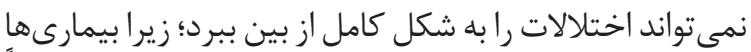

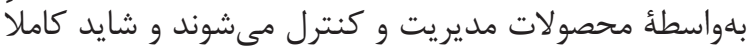

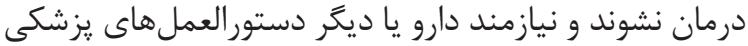

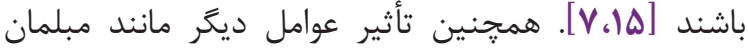

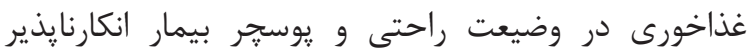

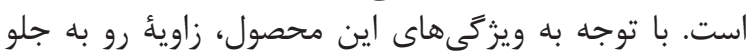

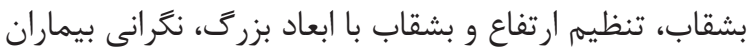

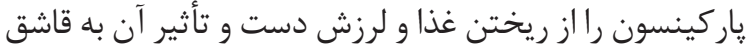

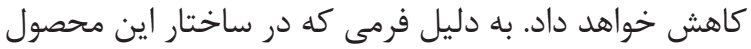

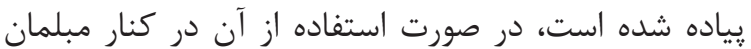

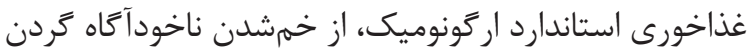

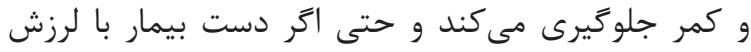

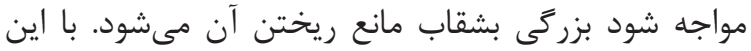

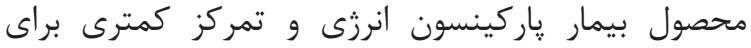
رساندن غذا به دهان خود نياز دارد كه در نهارين نهايت به كاريه كاهش سختى غذاخوردن بيمار منجر خواهد شدان شد نداز داند

جنس بدنهُ محصول از يلاستيك اي.بى.اس و بشقاب از

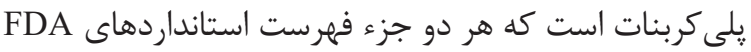

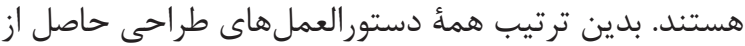

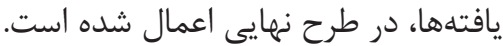

در يزوهش غفرانى و نورى (ع) • (T) با توجه به ميانگين

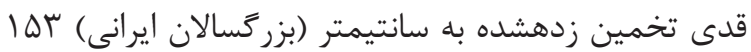

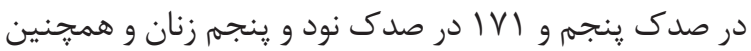

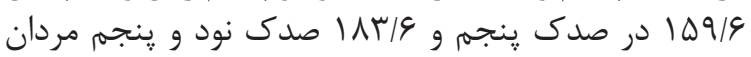

4. Poewe W, Seppi K, Tanner CM, Halliday GM, Brundin P, Volkmann J, et al. Parkinson disease. Nat Rev Dis Prim. 2017;3:1-21. https://doi. org/10.1038/nrdp.2017.13

5. Lee A, Gilbert RM. Epidemiology of Parkinson Disease. Vol. 34, Neurologic Clinics. 2016. p. 955-65. https://doi.org/10.1016/j. ncl.2016.06.012

6. Gazewood JD, Richards DR, Clebak K. Parkin- 
son disease: an update. Am Fam Physician. 2013 Feb 15;87(4):267-73.

7. Martin B, Hanington B, Hanington BM. Universal Methods of Design: 100 Ways to Research Complex Problems, Develop Innovative Ideas, and Design Effective Solutions. Rockport Publishers; 2012.

8. Solimeo S. With shaking hands: aging with Parkinson's disease in America's heartland. Rutgers University Press; 2009 Apr 15. http://rutgerspress.rutgers.edu

9. Nunes I, Bush P. Work-Related Musculoskeletal Disorders Assessment and Prevention. InTech. 2012. https://doi.org/10.5772/37229

10. Van der Marck MA, Dicke HC, Kentin ZHA, Borm GF, Bloem BR, Overeem S, et al. Abstract 218: Body weight in Parkinson's disease: a systematic review and meta-analysis. Mov Disord Abstr Fourteenth Int Congr Park Dis Mov Disord. 2010;25(S2):S257.

11. Wills AM, Li R, Pérez A, Ren X, Boyd J, NINDS NET-PD Investigators. Predictors of weight loss in early treated Parkinson's disease from the NET-PD LS-1 cohort. Journal of neurology. 2017 Aug 1;264(8):1746-53.

12. Sanders EB, Stappers PJ. Co-creation and the new landscapes of design. Co-design. 2008 Mar 1;4(1):5-18.

13. Mital A, Desai A, Subramanian A, Mital A., Pro- cess PD. Product Development. Product Development. 2014. 43-79.

14. Kluger BM. Fatigue in Parkinson's Disease. Int Rev Neurobiol. 2017: 133:743-68. https://doi. org/10.1016/bs.irn.2017.05.007

15. Ogrodnik P. Medical Device Design. 2013. https://books.google.com/books? $\mathrm{id}=\mathrm{oKmvtyCG}$ mh8C\&source $=$ gbs_navlinks_s

16. Muthya P, Raja A, Meghana A. Leveraging simulation for usability engineering of medical devices. In2018 10th International Conference on Communication Systems \& Networks (COMSNETS) 2018 Jan 3 (pp. 693-698). IEEE. https:// doi.org/10.1109/COMSNETS.2018.8328297

17. Tamsin M, Bach C. The Design of Medical Devices. Int. J. Innovation and Scientific Res.. 2014;1(2):127-32.

18. Gausepohl K, Winchester III WW, Arthur JD, Smith-Jackson T. Using storytelling to elicit design guidance for medical devices. Ergonomics in Design. 2011 Apr;19(2):19-24. https://doi. org/10.1177/1064804611408017

19. FDA/CDRH. Human Factors (Medical Devices) - Premarket Information - Device Design and Documentation Processes. FDA. 2018.

20. Gofrani M, Noori H. Design and Manufacture of Domestic Sofas with Ergonomic Indices. J Ergon. 2016; 4 (1) :64-71. https://doi.org/10.21859/ joe- 04018 